\title{
Hubungan kualitas hidup dan persepsi pasien tentang penyakit diabetes mellitus tipe 2 dengan komplikasi
}

\author{
Setiyo Budi Santoso', Dyah Aryani Perwitasari², Imaniar Noor Faridah ${ }^{2}$, A. A. Kaptein ${ }^{3}$ \\ ${ }^{1}$ Program Pascasarjana Farmasi Universitas Ahmad Dahlan \\ ${ }^{2}$ Fakultas Farmasi Universitas Ahmad Dahlan \\ Jl. Prof. Dr. Soepomo, Janturan, Yogyakarta 55164 \\ ${ }^{3}$ Medical Psychology-Leiden University Medical Center
}

\begin{abstract}
ABSTRAK
Kualitas hidup merupakan acuan penilaian outcome pasien diabetes mellitus tipe 2 (DMT2). Kualitas hidup pasien DMT2 dapat semakin menurun akibat komplikasi yang menyertainya. Aspek penting dalam pertimbangan intervensi peningkatan kualitas hidup adalah persepsi tentang penyakit. Tujuan penelitian ini untuk menguji pengaruh persepsi tentang penyakit terhadap kualitas hidup pasien DMT2 dengan komplikasi. Studi potong lintang terhadap populasi terjangkau berlangsung selama JuliSeptember 2015 di Poliklinik Penyakit Dalam Rumah Sakit PKU Muhammadiyah Bantul. Kuesioner Short Form-36 digunakan untuk mengukur kualitas hidup dan Brief-Illness Perceptions Questionnaire untuk persepsi tentang penyakit. Analisis uji $\mathrm{T}$ dan Anova satu jalan dilakukan untuk mengetahui perbedaan kualitas hidup dan persepsi tentang penyakit berdasarkan karakteristik dasar pasien (jenis kelamin, umur, pendidikan, pekerjaan, kadar gula darah sewaktu, tekanan darah, dan durasi diabetes), dan pengaruh persepsi tentang penyakit terhadap kualitas hidup. Penelitian melibatkan 51 pasien DMT2 dengan komplikasi. Subyek dengan tingkat pendidikan rendah memiliki peran fisik yang lebih buruk daripada subyek dengan pendidikan menengah dan tinggi $(\mathrm{p}=0,049)$. Persepsi subyek yang positif dapat meningkatkan kualitas hidup pada aspek: peran fisik $(\mathrm{p}=0,032)$, vitalitas $(\mathrm{p}=0,032)$, kesehatan mental $(\mathrm{p}=0,001)$, dan fungsi sosial $(\mathrm{p}=0,037)$. Kualitas hidup pasien DMT2 dengan komplikasi dipengaruhi oleh tingkat pendidikan dan persepsi tentang penyakit.
\end{abstract}

Kata kunci: diabetes melitus tipe 2 dengan komplikasi, kualitas hidup, SF-36, persepsi tentang penyakit, B-IPQ

\begin{abstract}
Quality of life (QoL) was developed as one of outcome measured for type 2 diabetes mellitus (T2DM) patients. The QoL may decrease due to its complications. QoL may also relate to illness perceptions. This study aims to assess the impact of illness perceptions on QoL in T2DM patient with complications. A cross sectional study was carried out at the Internist Departement of PKU Muhammadiyah Hospital, Bantul, Yogyakarta, on July-September 2015. Short Form 36 questionnaire was used to assess QoL and The Brief-Illness Perceptions Questionnaire was used for measuring subject's illness perceptions.
\end{abstract}

Penulis korespondesi:

Setiyo Budi Santoso

Pascasarjana Farmasi Universitas Ahmad Dahlan

J1. Prof. Dr. Soepomo, Janturan, Yogyakarta 55164

Email: apotekersetiyobudi@gmail.com 
Analysis of T-test and one way Anova to determine differences of QoL and illness perceptions among baseline (gender, age, education, occupation, plasma glucose, blood pressure, and duration of diabetes) and influence the illness perceptions on Qol. Fifty on T2DM patient with complications were studied. Subjects with low education level have worse physical role than subjects with middle and high education ( $\mathrm{p}=0.049)$. The positive illness perceptions can increase the value of the QoL on physical role $(\mathrm{p}=0.032)$, vitality $(\mathrm{p}=0.032)$ mental health $(\mathrm{p}=0.001)$, social function $(\mathrm{p}=0.037)$. This findings suggest that education level and illness perceptions are associated with quality of life.

Keywords: type 2 diabetes mellitus with complications, quality of life, SF-36, ilness perceptions, BIPQ

\section{PENDAHULUAN}

Populasi pasien diabetes melitus (DM) di Indonesia terus meningkat. Pada tahun 2000 sejumlah 8,4 juta jiwa, naik pada tahun 2013 menjadi 8,5 juta jiwa. WHO memprediksi peningkatan pada tahun 2030 menjadi 21,3 juta jiwa dengan dominasi tipe 2 sejumlah 90-95\% (Perkeni, 2006; Kemenkes RI, 2014; IDF, 2014; ADA, 2008). DM menempati peringkat ketiga (2\%) proporsi kasus baru rawat jalan penyakit tidak menular di rumah sakit dengan biaya pengeluaran $\$ 143$ per pasien (Kemenkes RI, 2012; IDF, 2014). Kematian disebabkan oleh DM mencapai 172.601 penderita pada tahun 2013 (IDF, 2014).

Kualitas hidup digunakan sebagai acuan dalam penilaian outcome pasien diabetes melitus tipe 2 (DMT2) (Sundaram et al., 2009). Penelitian sebelumnya melaporkan bahwa pasien DMT2 memiliki kualitas hidup lebih rendah dibandingkan populasi normal (Kiadaliri et al., 2013). Penurunan kualitas hidup akibat dari penyakit yang diderita maupun komplikasi yang menyertainya (Luscombe, 2000; Maddigan et al., 2006; Andayani et al., 2010).

Persepsi tentang penyakit merupakan pendekatan untuk menjelaskan perilaku dan cara individu dalam mengatasi penyakitnya (Weinman dan Petrie, 1997). Pendekatan ini merupakan aspek penting dalam pertimbangan intervensi peningkatan kualitas hidup pasien (Shallcross, et al., 2015; Ashley et al., 2015; Taylor, 2012). Persepsi diri yang positif berpengaruh terhadap kualitas hidup yang baik (Taylor, 2012).

Tujuan penelitian ini untuk mengukur kualitas hidup dan persepsi tentang penyakit pasien DMT2 dengan komplikasi, sehingga diketahui hubungan antara persepsi tentang penyakit terhadap kualitas hidup.

\section{METODE PENELITIAN}

Jenis penelitian adalah observasional analitik dengan metode cross sectional. Penelitian berlangsung selama bulan Juli-September 2015 di Poliklinik Penyakit Dalam RS PKU Muhammadiyah Bantul. Kriteria inklusi penelitian meliputi: pasien dengan diagnosa DMT2, durasi penyakit lebih dari 3 bulan, pasien dengan komplikasi, dan pasien bersedia menjadi subyek penelitian. Kriteria eksklusi penelitian adalah ibu hamil dan pasien yang mengisi kuesioner secara tidak lengkap.

Pengukuran kualitas hidup menggunakan kuesioner (Short Form) SF-36. Kuesioner terdiri 36 pertanyaan yang mencakup 8 domain: fungsi fisik (FF), peran fisik (PF), peran emosi (PE), vitalitas $(\mathrm{V})$, kesehatan mental (KM), fungsi sosial (FS), dan nyeri (N) dan kesehatan umum (KU). Kuesioner SF-36 versi Bahasa Indonesia telah tersedia, meskipun uji reliabilitas dan validitasnya butuh untuk dikembangkan (Perwitasari, 2012).

Persepsi tentang penyakit diukur dengan kuesioner instrumen Brief-Illness Perceptions Questionnaire (B-IPQ). Kuesioner terdiri 9 item pertanyaan (8 domain dan 1 kausal). Interpretasi skor skala persepsi tentang penyakit dipaparkan melalui skala kategorisasi ordinal. Estimasi luas interval yang mencakup setiap kategorisasi mengacu pada besaran mean dan standar deviasi (SD) populasi. Kategorisasi persepsi terhadap penyakit disusun dengan 5 skala (sangat positif, positif, netral, negatif, dan sangat negatif) (Tabel I) (Azwar, 2012).

Pharmaciana Vol. 7, No. 1, Mei 2017, Hal. 33 - 40 
Tabel I. Kategori skor persepsi tentang penyakit

\begin{tabular}{lccc}
\hline & Rumus & & Kategori \\
\hline & $\mathrm{X}<$ & $($ Mean - 1,5 SD) & Sangat Positif \\
Mean - 1,5 SD) & $\leq \mathrm{X}<$ & (Mean - 0,5 SD) & Positif \\
(Mean - 0,5 SD) & $\leq \mathrm{X}<$ & (Mean + 0,5 SD) & Netral \\
Mean + 0,5 SD) & $\leq \mathrm{X}<$ & $($ Mean + 1,5 SD) & Negatif \\
$($ Mean + 1,5 SD) & $\leq \mathrm{X}$ & & Sangat Negatif \\
\hline
\end{tabular}

Data hasil penelitian dianalisis dengan instrumen statistical package for the social science (SPSS) versi 21. Analisis univariat dengan uji deskripsi dan frekuensi, dilakukan untuk mengetahui distribusi karakteristik dasar pasien (jenis kelamin, umur, pendidikan, pekerjaan, kadar GDS, tekanan darah, dan durasi diabetes). Analisis bivariat dengan uji T dan Anova satu jalan, untuk mengetahui perbedaan kualitas hidup dan persepsi tentang penyakit berdasarkan karakteristik dasar, dan pengaruh persepsi tentang penyakit terhadap kualitas hidup. Hipotesis diterima apabila nilai $p<0,05$.

\section{HASIL DAN PEMBAHASAN Profil kualitas hidup}

Perbedaan nilai kualitas hidup pasien DMT2 dengan komplikasi berdasarkan karakteritik dapat dilihat pada Tabel II. Karakteristik dasar tidak memberikan perbedaan signifikan terhadap kualitas hidup subyek, kecuali tingkat pendidikan. Tingkat pendidikan berpengaruh terhadap peran fisik subyek $(\mathrm{p}=0,049)$. Kelompok subyek dengan tingkat pendidikan yang rendah $(32,95 \pm 38,099)$ lebih membatasi peran fisiknya daripada kelompok dengan tingkat pendidikan tinggi $(58,33 \pm 37,401)$ dan menengah $(62,50 \pm 40,132)$.

Penelitian di Iran telah membuktikan hubungan tingkat pendidikan yang tinggi dengan peningkatan nilai kualitas hidup. Pasien DMT2 dengan pendidikan lebih tinggi memiliki pemahaman yang lebih baik tentang penyakitnya. Mereka mampu mengelola dampak yang muncul akibat penyakit berikut penatalaksanaanya secara mandiri sesuai kemampuan yang dimiliki (Javanbakht et al., 2012). Tingkat pendidikan juga berkaitan dengan perolehan pengetahuan individu. Pasien dengan pengetahuan yang layak memiliki kesadaran untuk merubah gaya hidup ke arah yang lebih sehat dan hidup yang berkualitas (Gultom, 2012).

\section{Profil persepsi tentang penyakit}

Persepsi tentang penyakit yang dimiliki pasien DMT2 dengan komplikasi tidak dipengaruhi oleh karakteristik. Tabel III menunjukkan bahwa skor persepsi tentang penyakit antar kelompok karakteristik tidak berbeda signifikan.

\section{Pengaruh persepsi tentang penyakit terhadap kualitas hidup}

Hasil analisis uji known group pada variabel persepsi tentang penyakit terhadap kualitas hidup dapat dilihat pada Tabel IV. Persepsi penyakit yang positif dapat meningkatkan kualitas hidup pada aspek; peran fisik $(77,08 \pm 31,003 ; \mathrm{p}=0,032)$, vitalitas $(75,00 \pm 15,000 ; \mathrm{p}=0,032)$, kesehatan mental $(82,67 \pm 16,211 ; \mathrm{p}=0,001)$, dan fungsi sosial $(77,67 \pm 28,550 ; \mathrm{p}=0,037)$. 
Tabel II. Perbedaan nilai kualitas hidup berdasarkan karakteristik

\begin{tabular}{|c|c|c|c|c|c|c|c|c|c|c|}
\hline \multicolumn{2}{|c|}{ Karakteristik } & \multirow{2}{*}{$\begin{array}{c}\mathbf{N} \\
23\end{array}$} & \multirow{2}{*}{$\begin{array}{c}\text { FF } \\
\text { Mean } \\
\text { SD } \\
71,44\end{array}$} & \multirow{2}{*}{$\begin{array}{c}\text { PF } \\
\text { Mean } \\
\text { SD } \\
54,35\end{array}$} & \multirow{2}{*}{$\begin{array}{c}\text { PE } \\
\text { Mean } \\
\text { SD } \\
50,72\end{array}$} & \multirow{2}{*}{$\begin{array}{c}\mathrm{V} \\
\text { Mean } \\
\text { SD } \\
66,96\end{array}$} & \multirow{2}{*}{$\begin{array}{c}\mathbf{K M} \\
\text { Mean } \\
\text { SD } \\
73,39\end{array}$} & \multirow{2}{*}{$\begin{array}{c}\text { FS } \\
\text { Mean } \\
\text { SD } \\
40,54\end{array}$} & \multirow{2}{*}{$\begin{array}{c}\mathbf{N} \\
\text { Mean } \\
\text { SD } \\
56,52\end{array}$} & \multirow{2}{*}{$\begin{array}{c}\mathrm{KU} \\
\text { Mean } \\
\text { SD } \\
49,13\end{array}$} \\
\hline Jenis & Laki-laki & & & & & & & & & \\
\hline \multirow[t]{4}{*}{ kelamin } & & & 29,859 & 39,638 & 41,279 & 14,040 & 16,911 & 25,719 & 24,963 & 13,112 \\
\hline & Perempuan & 28 & 61,48 & 43,75 & 36,90 & 64,46 & 66,65 & 40,82 & 50,00 & 45,54 \\
\hline & & & 35,070 & 40,612 & 38,851 & 16,406 & 19,357 & 26,331 & 24,533 & 11,574 \\
\hline & Nilai $p$ & & 0,279 & 0,352 & 0,228 & 0,562 & 0,191 & 0,970 & 0,354 & 0,310 \\
\hline \multirow[t]{5}{*}{ Usia } & $<60$ tahun & 32 & 65,13 & 50,00 & 43,75 & 64,22 & 67,07 & 40,25 & 55,47 & 45,78 \\
\hline & & & 36,030 & 40,161 & 39,201 & 15,351 & 18,256 & 25,684 & 25,188 & 14,091 \\
\hline & $\geq 60$ tahun & 19 & 67,39 & 46,05 & 42,11 & 67,89 & 74,11 & 41,45 & 48,68 & 49,47 \\
\hline & & & 27,661 & 41,048 & 42,806 & 15,304 & 18,348 & 26,673 & 23,897 & 8,316 \\
\hline & Nilai $p$ & & 0,802 & 0,740 & 0,892 & 0,413 & 0,193 & 0,876 & 0,343 & 0,305 \\
\hline \multirow{7}{*}{$\begin{array}{l}\text { Tingkat } \\
\text { Pendidi- } \\
\text { kan }\end{array}$} & Dasar & 22 & 62,95 & 32,95 & 33,33 & 63,18 & 66,46 & 31,64 & 49,43 & 46,82 \\
\hline & & & 36,957 & 38,099 & 38,490 & 15,777 & 17,485 & 22,808 & 29,499 & 11,907 \\
\hline & Menengah & 14 & 74,29 & 62,50 & 54,76 & 66,79 & 71,14 & 43,54 & 50,89 & 42,86 \\
\hline & & & 31,736 & 40,132 & 40,525 & 15,518 & 18,904 & 27,424 & 19,894 & 10,869 \\
\hline & Tinggi & 15 & 62,64 & 58,33 & 46,67 & 68,00 & 73,07 & 51,33 & 60,00 & 51,67 \\
\hline & & & 27,987 & 37,401 & 41,404 & 14,856 & 19,797 & 25,292 & 20,702 & 13,318 \\
\hline & Nilai $p$ & & 0,549 & $0,049 *$ & 0,278 & 0,614 & 0,541 & 0,063 & 0,422 & 0,154 \\
\hline \multirow{5}{*}{$\begin{array}{l}\text { Kadar } \\
\text { Gula } \\
\text { Darah } \\
\text { Sewaktu }\end{array}$} & $<200$ & 28 & 62,44 & 40,18 & 38,10 & 66,61 & 72,51 & 42,98 & 51,34 & 49,82 \\
\hline & & & 34,577 & 38,091 & 37,090 & 16,390 & 18,265 & 27,264 & 24,138 & 12,056 \\
\hline & $\geq 200$ & 23 & 70,28 & 58,70 & 49,28 & 64,35 & 66,26 & 37,91 & 54,89 & 43,91 \\
\hline & & & 30,910 & 41,016 & 43,658 & 14,086 & 18,442 & 24,195 & 25,766 & 12,056 \\
\hline & Nilai $p$ & & 0,397 & 0,104 & 0,336 & 0,599 & 0,233 & 0,485 & 0,617 & 0,088 \\
\hline \multirow{5}{*}{$\begin{array}{l}\text { Tekanan } \\
\text { Darah }\end{array}$} & $<140 / 90$ & 16 & 65,88 & 43,75 & 39,58 & 70,63 & 76,25 & 38,75 & 55,47 & 49,69 \\
\hline & & & 33,871 & 41,332 & 40,768 & 16,520 & 17,311 & 31,940 & 21,394 & 13,961 \\
\hline & $\geq 140 / 90$ & 35 & 66,01 & 50,71 & 44,76 & 63,29 & 66,69 & 41,59 & 51,79 & 46,00 \\
\hline & & & 32,929 & 39,984 & 40,376 & 14,346 & 18,378 & 22,934 & 26,280 & 11,492 \\
\hline & Nilai $p$ & & 0,990 & 0,577 & 0,676 & 0,138 & 0,083 & 0,752 & 0,600 & 0,365 \\
\hline \multirow{6}{*}{$\begin{array}{l}\text { Status } \\
\text { Pekerja- } \\
\text { an }\end{array}$} & Bekerja & 29 & 68,47 & 52,59 & 45,98 & 64,14 & 68,77 & 39,95 & 56,47 & 48,79 \\
\hline & & & 32,184 & 38,000 & 38,228 & 14,083 & 16,995 & 24,582 & 23,769 & 13,273 \\
\hline & Tak & 22 & 62,69 & 43,18 & 39,39 & 67,50 & 70,91 & 41,68 & 48,30 & 45,00 \\
\hline & Bekerja & & 34,265 & 43,082 & 43,200 & 16,885 & 20,515 & 27,874 & 25,674 & 10,801 \\
\hline & & & 0,544 & 0,421 & 0,574 & 0,454 & 0,693 & 0,818 & 0,252 & 0,266 \\
\hline & Nilai $p$ & & & & & & & & & \\
\hline \multirow{5}{*}{$\begin{array}{l}\text { Durasi } \\
\text { Penyakit }\end{array}$} & $\leq 5$ tahun & 23 & 70,79 & 54,35 & 47,83 & 66,30 & 68,35 & 34,61 & 58,15 & 44,78 \\
\hline & & & 30,986 & 41,732 & 41,226 & 11,303 & 15,721 & 20,485 & 17,921 & 12,746 \\
\hline & $>5$ tahun & 28 & 62,01 & 43,75 & 39,29 & 65,00 & 70,79 & 45,70 & 48,66 & 49,11 \\
\hline & & & 34,416 & 38,864 & 39,600 & 18,105 & 20,611 & 28,860 & 28,735 & 11,789 \\
\hline & Nilai $p$ & & 0,343 & 0,357 & 0,457 & 0,765 & 0,642 & 0,128 & 0,157 & 0,219 \\
\hline
\end{tabular}

*Nilai $p<0,05$ menunjukkan perbedaan signikan antar kelompok karakteristik.

FF: Fungsi Fisik; PF: Peran Fisik; PE: Peran Emosi; V: Vitalitas; KM: Kesehatan Mental; FS: Fungsi Sosial; N: Nyeri; KU: Kesehatan Umum. 
Tabel III. Perbedaan skor persepsi tentang penyakit berdasarkan karakteristik

\begin{tabular}{|c|c|c|c|c|}
\hline \multirow{2}{*}{\multicolumn{2}{|c|}{ Karakteristik }} & \multirow{3}{*}{$\frac{\mathbf{N}}{23}$} & \multicolumn{2}{|c|}{ Skor persepsi tentang penyakit } \\
\hline & & & Mean \pm SD & Nilai $p$ \\
\hline \multirow[t]{2}{*}{ Jenis Kelamin } & Laki-laki & & $31,74 \pm 7,219$ & 0,973 \\
\hline & Perempuan & 28 & $31,82 \pm 9,892$ & \\
\hline \multirow[t]{2}{*}{ Umur } & $<60$ tahun & 32 & $33,16 \pm 9,095$ & 0,130 \\
\hline & $\geq 60$ tahun & 19 & $29,47 \pm 7,684$ & \\
\hline \multirow[t]{3}{*}{ Pendidikan } & Dasar & 22 & $32,68 \pm 9,648$ & 0,213 \\
\hline & Menengah & 14 & $33,86 \pm 8,037$ & \\
\hline & Tinggi & 15 & $28,53 \pm 7,357$ & \\
\hline \multirow[t]{2}{*}{ Gula Darah Sewaktu } & $<200$ & 28 & $31,57 \pm 8,552$ & 0,850 \\
\hline & $\geq 200$ & 23 & $32,04 \pm 9,073$ & \\
\hline \multirow[t]{2}{*}{ Tekanan Darah } & $<140 / 90$ & 16 & $30,44 \pm 9,295$ & 0,479 \\
\hline & $\geq 140 / 90$ & 35 & $32,40 \pm 8,489$ & \\
\hline \multirow[t]{2}{*}{ Pekerjaan } & Bekerja & 29 & $30,97 \pm 8,986$ & 0,442 \\
\hline & Tidak Bekerja & 22 & $32,86 \pm 8,402$ & \\
\hline \multirow[t]{4}{*}{ Durasi Penyakit } & $\leq 5$ tahun & 23 & $33,48 \pm 7,070$ & 0,197 \\
\hline & $>5$ tahun & 28 & $30,39 \pm 9,754$ & \\
\hline & tal & 51 & & \\
\hline & & & $31,78 \pm 8,705$ & \\
\hline
\end{tabular}

*Skor yang lebih tinggi mencerminkan persepsi yang negative

Prinsip penilaian kualitas hidup adalah mengukur sejauh mana pasien dapat melaksanakan aktivitas dalam kehidupannya secara normal meskipun terganggu oleh penyakit dan dampak dari terapi (Taylor, 2012). Aktivitas keseharian pasien DMT2 dengan komplikasi sangat terkait dengan bangunan persepsi yang dimilikinya. Pasien membangun persepsi tentang penyakit melalui proses kognisi dan emosi, sebagai dasar perilaku dalam mengelola penyakit yang dideritanya (Petrie dan Weinman, 2012; Leventhal dan Cameron, 2003)

Cara pasien dalam memahami penyakit merupakan faktor yang membantu pemulihan dan pengelolaan penyakit mereka (Faria et al., 2013). Pasien yang meyakini dirinya dalam keadaan baik akan memiliki dimensi fisik, mental dan mood yang positif (Taylor 2012; Pakenham, 2005). Sebaliknya pasien dengan persepsi yang negatif akan mengalami penurunan kualitas hidup (Paschalides et al., 2004).

Keterbatasan penelitian ini tidak mengukur pengaruh masing-masing jenis komplikasi terhadap kualitas hidup pasien. Jumlah sampel yang lebih besar mungkin dapat menurunkan nilai simpangan baku. 
Tabel IV. Hasil uji beda persepsi tentang penyakit terhadap kualitas hidup

\begin{tabular}{|c|c|c|c|c|c|c|c|c|c|}
\hline \multicolumn{3}{|c|}{ Persepsi Tentang Pen } & \multicolumn{7}{|c|}{ Kualitas Hidup } \\
\hline Kat & $\mathbf{S}$ & $\mathbf{N}$ & $\begin{array}{c}\text { FF } \\
\text { Mean } \\
\text { SD }\end{array}$ & $\begin{array}{c}\text { PF } \\
\text { Mean } \\
\text { SD }\end{array}$ & $\begin{array}{c}\text { PE } \\
\text { Mean } \\
\text { SD }\end{array}$ & $\begin{array}{c}\mathrm{V} \\
\text { Mean } \\
\text { SD }\end{array}$ & $\begin{array}{c}\text { KM } \\
\text { Mean } \\
\text { SD }\end{array}$ & $\begin{array}{c}\text { FS } \\
\text { Mean } \\
\text { SD }\end{array}$ & $\begin{array}{c}\mathbf{N} \\
\text { Mean } \\
\text { SD }\end{array}$ \\
\hline Sangat Positif & $10-18$ & 3 & & & $\begin{array}{c}22,22 \\
38,490\end{array}$ & & & $\begin{array}{c}77,67 \\
28,550\end{array}$ & $\begin{array}{r}58,33 \\
26,021\end{array}$ \\
\hline Posi & $19-27$ & 12 & & & & & & & \\
\hline Netral & $28-36$ & 18 & & & & & & $\begin{array}{c}39,64 \\
20,771\end{array}$ & $\begin{array}{r}54,17 \\
29,079\end{array}$ \\
\hline Negatif & $37-45$ & 16 & & & & & & & $\begin{array}{c}49,22 \\
23,483\end{array}$ \\
\hline Sangat Negatif & $46-49$ & 2 & & & & & & & $\begin{array}{c}37,50 \\
17,678\end{array}$ \\
\hline 1la & 9 & 51 & $\begin{array}{c}65,97 \\
32,887 \\
0,058\end{array}$ & $\begin{array}{l}48,53 \\
40,128 \\
\mathbf{0 . 0 3 2}\end{array}$ & $\begin{array}{l}43,14 \\
40,163 \\
0,327\end{array}$ & $\begin{array}{c}65,59 \\
15,286 \\
\mathbf{0 . 0 3 2}\end{array}$ & $\begin{array}{c}69,69 \\
18,430 \\
\mathbf{0 , 0 0 1}\end{array}$ & $\begin{array}{l}40,70 \\
25,797 \\
\mathbf{0 . 0 3 7}\end{array}$ & $\begin{array}{c}52,94 \\
24,697 \\
0,803\end{array}$ \\
\hline
\end{tabular}

* Mean yang tercetak tebal menunjukkan nilai kualitas hidup tertinggi

**Nilai $p<0,05$ menunjukkan perbedaan signikan antar kelompok karakteristik.

FF: Fungsi Fisik; PF: Peran Fisik; PE: Peran Emosi; V: Vitalitas; KM: Kesehatan Mental; FS: Fungsi Sosial; N: Nyeri;

\section{KESIMPULAN}

Hasil penelitian terhadap pasien DMT2 dengan komplikasi di Poliklinik Penyakit Dalam Rumah Sakit PKU Muhammadiyah Bantul, menunjukkan bahwa tingkat pendidikan dan persepsi tentang penyakit yang dimiliki pasien berpengaruh terhadap kualitas hidupnya.

\section{UCAPAN TERIMAKASIH}

Kepada Rumah Sakit PKU Muhammadiyah Bantul beserta staf yang telah memberikan izin dan membantu kegiatan penelitian ini, serta seluruh pihak yang telah memberikan kontribusi dalam penulisan karya ilmiah ini.

\section{DAFTAR PUSTAKA}

American Diabetes Association (ADA), 2008, Diagnosis and classification of diabetes mellitus, Diabetes Care,31(1): S55-S60.

Andayani, T.M., Ibrahim, M.I.M, dan Asdie, A., 2010, The Association of diabetes-related factor and quality of life in type 2 diabetes mellitus, International Journal of Pharmacy and Pharmaceutical Sciences, 2(1): 139-145.

Ashley, L., Marti, J., Jones, H., Velikova, G., dan Wright, P., 2015, Illness perceptions within 6 months of cancer diagnosis are an independent prospective predictor of health-related quality of life 15 months post-diagnosis, Psycho-Oncology 24 (11): 1463-1470.

Azwar, S., 2012, Penyusunan Skala Psikologi Ed. II, Pustaka Pelajar, Yogyakarta: 145-150.

Faria, H. T. G., Veras, V. S., Xavier, A. T. F., Teixeira, C. R. S., Zanetti,M. L., dan Santos, M. A., 2012, Quality of life in patients with diabetes mellitus before and after their participation in an educational program, Revista da Escola de Enfermagem da USP, 47(2):344-349

Gultom, Y.T., 2012, Tingkat Pengetahuan Pasien Diabetes Mellitus Tentang Manajemen Diabetes Mellitus Di Rumah Sakit Pusat Angkatan Darat Gatot Soebroto Jakarta Pusat, Skripsi, Fakultas Keperawatan Universitas Indonesia, Depok.

International Diabetes Federation (IDF), 2014, http://www.idf.org/membership/wp/indonesia, diakses tanggal 15 November 2014. 
Javanbakht, M., Abolhasani, F., Mashayekhi, A., Baradaran, H.R., Noudeh, Y.J., 2012, Health related quality of life in patients with type 2 diabetes mellitus in Iran: A national survey, PloS ONE, 7(8): e445261 - e445269.

Kemenkes RI, 2012, Jendela Data dan Informasi Kesehatan: Penyakit Tidak Menular, 2(2): 1-41

Kemenkes RI, 2014, Situasi dan Analisis Diabetes, Jakarta: Kemenkes RI.

Kiadaliri, A.A., Najafi, B., dan Mirmalek-Sani, M., 2013, Quality of life in people with diabetes: a systematic review of studies in Iran, Journal of Diabetes \& Metabolic Disorders, 12(54): 1-10.

Leventhal, H., \& Cameron, L. D, 2003, The Self-Regulation of Health and Illness Behaviour, London: Routledge.

Luscombe, F.A., 2000, Health-related quality of life measurement in type 2 diabetes, Value Health, 3(1): S15-S28.

Maddigan, S.L., Feeny, D.H., Majumdar, S.R., Farris, K.B.,dan Johnson, J.A., 2006, Understanding the determinants of health for people with type 2 diabetes, American Journal of Public Health, 96(9): 1649-1655.

Pakenham, K.I., 2005, Benefit finding in multiple sclerosis and associations with positive and negative outcomes, Health Psychology, 24(2):123-132.

Paschalides, C., Wearden, A.J., Dunkerley, R., Bundy, C., Davies, R., dan Dickens, C.M., 2004, The associations of anxiety, depression and personal illness representations with glycaemic control and health-related quality of life in patients with type 2 diabetes mellitus, Journal of Psychosomatic Research: 57: 557-564.

Perkeni, 2006, Konsesus Pengelolaan dan Pencegahan Diabetes Mellitus Tipe 2, Persatuan Endokrinologi Indonesia, Jakarta: 1-70.

Perwitasari, D.A., 2012, Development the validation of indonesian version of SF-36 questionnaire in cancer disease, Indonesian J. Pharm, 23 (4): 248-253.

Petrie, K.J., dan Weinman, J., 2012, Patients' perceptions of their illness: the dynamo of volition in health care, Current Directions in Psychological Science, 21(1): 60-65.

Shallcross, A.J., Becker D.A., Singh, A., Friedman, D, Montesdeoca, J., French, J., Devinsky, O., dan Spruill, T.M., 2015, Illness perceptions mediate the relationship between depression and quality of life in patients with epilepsy. Epilepsia, 56(11):e186-90.

Sundaram, M., Kavookjian, J., dan Patrick, J.H., 2009, Health related-quality of life and quality of life in type 2 diabetes melitus; relationship in a cross sectional study, Patient, 1(2): 121-33.

Taylor, S. E., 2012, Health Psychology Eighth Edition, McGraw-Hill, New York: 258-284.

Weinman, J., dan Petrie, K.J., 1997, Illness perceptions: A new paradigm for psychosomatics?, Journal of Psychosomatic Research, 42, (2) 113-116. 
Pharmaciana Vol. 7, No. 1, Mei 2017, Hal. 33 - 40 